\title{
Consumption of added fats and oils in the European Prospective Investigation into Cancer and Nutrition (EPIC) centres across 10 European countries as assessed by 24 -hour dietary recalls
}

\author{
J Linseisen ${ }^{1,2, *}$, E Bergström ${ }^{3}$, L Gafá $^{4}$, CA González ${ }^{5}$, A Thiébaut ${ }^{6}$, A Trichopoulou ${ }^{7}$, \\ R Tumino ${ }^{4}$, C Navarro Sánchez ${ }^{8}$, C Martínez Garcia ${ }^{9}$, I Mattisson $^{10}$, S Nilsson ${ }^{11}$, \\ A Welch ${ }^{12}$, EA Spencer ${ }^{13}$, K Overvad $^{14}$, A Tiønneland ${ }^{15}$, F Clavel-Chapelon $^{6}$, E Kesse ${ }^{6}$, \\ AB Miller ${ }^{2}, M$ Schulz ${ }^{16}, K^{\prime}$ Botsi ${ }^{7}$, A Naska ${ }^{7}, S$ Sieri ${ }^{17}, C^{\prime}$ Sacerdote ${ }^{18}$, MC Ooké $^{19}$,

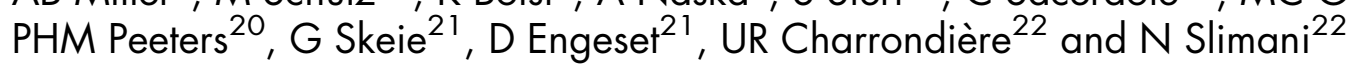 \\ 'Unit of Human Nutrition and Cancer Prevention, Technical University of Munich, Alte Akademie 16, D-85350 \\ Freising-Weihenstephan, Germany: ${ }^{2}$ Division of Clinical Epidemiology, German Cancer Research Centre, \\ Heidelberg, Germany: ${ }^{3}$ Department of Public Health and Clinical Medicine, Epidemiology, Umeå University, \\ Sweden: ${ }^{4}$ Cancer Registry, 'Civile - M.P. Arezzo' Hospital, Ragusa, Italy: ${ }^{5}$ Department of Epidemiology, Catalan \\ Institute of Oncology, Barcelona, Spain: 'INSERM, E3N-EPIC Group, Institute Gustave Roussy, Villejuif, France: \\ ${ }^{7}$ Department of Hygiene and Epidemiology, School of Medicine, University of Athens, Greece: ${ }^{8}$ Department of \\ Epidemiology, Health Council of Murcia, Spain: ${ }^{9}$ Granada Cancer Registry, Andalusian School of Public Health, \\ Granada, Spain: ${ }^{10}$ Department of Medicine, Surgery and Orthopaedics, University of Lund, Malmö, Sweden: \\ ${ }^{11}$ Department of Public Health and Clinical Medicine, Umeå University, Sweden: ${ }^{12}$ Department of Public Health and \\ Primary Care, School of Clinical Medicine, University of Cambridge, UK: ${ }^{13}$ Cancer Research UK, Epidemiology \\ Unit, University of Oxford, UK: ${ }^{14}$ Department of Epidemiology and Social Medicine, University of Aarhus, Denmark: \\ ${ }^{15}$ Institute of Cancer Epidemiology, Danish Cancer Society, Copenhagen, Denmark: ${ }^{16}$ Department of Epidemiology, \\ German Institute of Human Nutrition, Potsdam-Rehbrücke, Germany: ${ }^{17}$ Epidemiology Unit, National Cancer Institute, \\ Milan, Italy: ${ }^{18}$ Unit of Cancer Epidemiology, University of Turin, Italy: ${ }^{19}$ Department of Chronic Diseases \\ Epidemiology, National Institute for Public Health and the Environment, Bilthoven, The Netherlands: ${ }^{20}$ Julius Center \\ for General Practice and Patient Oriented Research, University of Utrecht, The Netherlands: ${ }^{21}$ Institute of Community \\ Medicine, University of Tromsø, Norway: ${ }^{22}$ International Agency for Research on Cancer, Lyon, France
}

\begin{abstract}
Objective: To evaluate the consumption of added fats and oils across the European centres and countries participating in the European Prospective Investigation into Cancer and Nutrition (EPIC).

Design and setting: 24-Hour dietary recalls were collected by means of standardised computer-guided interviews in 27 redefined EPIC centres across 10 European countries.

Subjects: From an initial number of 36900 subjects, single dietary recalls from 22924 women and 13031 men in the age range of 35-74 years were included.

Results: Mean daily intake of added fats and oils varied between $16.2 \mathrm{~g}$ (Varese, Italy) and $41.1 \mathrm{~g}$ (Malmö, Sweden) in women and between $24.7 \mathrm{~g}$ (Ragusa, Italy) and $66.0 \mathrm{~g}$ (Potsdam, Germany) in men. Total mean lipid intake by consumption of added fats and oils, including those used for sauce preparation, ranged between 18.3 (Norway) and $37.2 \mathrm{~g} \mathrm{day}^{-1}$ (Greece) in women and 28.4 (Heidelberg, Germany) and $51.2 \mathrm{~g} \mathrm{day}^{-1}$ (Greece) in men. The Mediterranean EPIC centres with high olive oil consumption combined with low animal fat intake contrasted with the central and northern European centres where fewer vegetable oils, more animal fats and a high proportion of margarine were consumed. The consumption of added fats and oils of animal origin was highest in the German EPIC centres, followed by the French. The contribution of added fats and oils to total energy intake ranged from $8 \%$ in Norway to $22 \%$ in Greece.

Conclusions: The results demonstrate a high variation in dietary intake of added fats and oils in EPIC, providing a good opportunity to elucidate the role of dietary fats in cancer aetiology.
\end{abstract}

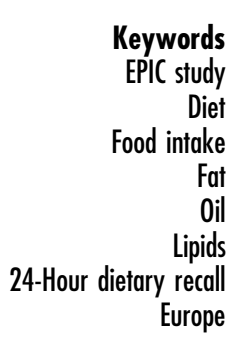


There is evidence from both epidemiological and experimental studies that the types of fat consumed as well as the amounts may influence the development and subsequent progression of a number of chronic diseases, including obesity and obesity-related diseases, coronary heart disease and cancer ${ }^{1,2}$. Besides the question of a balanced energy intake and energy expenditure, it has been suggested that diets high in fat increase the risk of becoming overweight, although results from experimental and intervention studies do not support this ${ }^{3-7}$. However, high priority is given to the control of fat intake for obesityrelated diseases such as non-insulin-dependent diabetes mellitus, hypertension and hyperlipoproteinaemia ${ }^{8}$. The association between level of dietary lipid intake and cardiovascular disease risk is well established. Owing to the availability of plasma lipoproteins as intermediate effect markers, the different effects of saturated, monounsaturated, $n-6$ polyunsaturated, $n-3$ polyunsaturated and trans-fatty acids have been described along with the underlying biological mechanisms ${ }^{9,10}$. However, the scientific evidence for a significant decrease in cardiovascular disease risk (morbidity and mortality) by lowering and modifying fat intake, and thus affecting plasma lipoproteins, is not straightforward ${ }^{11,12}$. Identification of the role of fat and fatty acids in carcinogenesis is even more difficult, mainly due to the absence of intermediate effect markers. Besides plausible biological explanations, the epidemiological evidence is not strong for most cancer sites $^{13-15}$.

Consumption of added fats and oils provides an important contribution to total lipid intake. At the food level, there may be further interesting compounds in addition to the fat content and the fatty acid pattern of fats and oils. Minor food components such as tocopherols, polyphenols in native olive oil and conjugated linoleic acid in ruminant fat (e.g. butter, dairy products) are also thought to have effects on health ${ }^{10,16,17}$.

The supply of added fats and oils in Europe is diverse and has changed considerably over the last 50 years, in central and northern Europe as well as in the more southern areas ${ }^{18-20}$. This is due to changes in the agricultural and industrial production of fats and oils as well as to changes in consumer habits and attitudes, not least influenced by health claims in terms of reduction of blood cholesterol levels. In the British diet, for example, the consumption of ruminant fat (e.g. butter, dairy cream) has declined over the past century and that of vegetable oil and margarine has increased, leading to a much higher linoleic acid intake. Similar changes have taken place in The Netherlands and Sweden ${ }^{18}$. In contrast, olive oil is still the dominant dietary lipid source in the Mediterranean countries $^{19,21}$.

The European Prospective Investigation into Cancer and Nutrition (EPIC), as a European multi-centre study focusing on the effect of diet on cancer development, is able to give further insight into the role of dietary fat in cancer aetiology. However, this implies an extensive and precise knowledge of the individual exposure level of the participants. At present, a common international or European surveillance system providing comparable information on the dietary intake of added fats and oils at the individual level is not available. Comparable data on food availability at the household level are available through the DAFNE (DAta Food NEtworking) databank ${ }^{22-24}$. With the highly standardised 24-hour recall technique applied in all EPIC centres ${ }^{25}$, a high-quality source of recent dietary intake data for comparison of differences between participating European centres is available. Making use of these data, the present paper aims to describe the intake of added fats and oils in EPIC centres across 10 European countries, also taking into account the contribution of fats and oils used as an ingredient for sauce preparation.

\section{Subjects and methods}

The EPIC cohort includes about half a million subjects from 10 European countries. Information on the usual diet of all participants has been assessed by country-specific instruments. In order to adjust (at the group level) for systematic measurement error between countries, highly standardised 24-hour recalls were performed on a subsample of the cohort as an additional dietary measurement ${ }^{26}$. The aim was to collect 24-hour recalls in a stratified random sample of $5-12 \%$ (1.5\% in the UK) of all centre-specific cohorts considering the expected cancer incidence in gender- and age-specific strata ${ }^{27}$. This original sample included 36900 subjects but was reduced to 35955 participants after exclusion of subjects under 35 and over 74 years of age. The participants in this calibration study, therefore, should reflect the centre-specific EPIC cohorts, but not the general population in the centre area or country (with few exceptions, e.g. Norway). The present evaluation is based on single 24-hour recalls from 22924 women and 13031 men participating in the EPIC calibration study between 1995 and 1998 (except Norway: 1999-2000). The distribution of the study participants over the 27 redefined EPIC study centres is given in the tables; in France, Norway, Utrecht (The Netherlands) and Naples (Italy), only women were recruited. In France, Greece and Norway, study participants were recruited from all over the country; study regions were defined $a$ posteriori in France and Norway. All participants included in the present analyses were in the age range of 35-74 years at recruitment. A detailed description of further characteristics of the study participants is given elsewhere in this supplement ${ }^{27}$.

A computerised 24-hour dietary recall interview program, called EPIC-SOFT, was developed as a calibration instrument by the International Agency for Research on Cancer in co-operation with all EPIC study centres $^{25,28}$. The program was adapted for each participating country in terms of foods and recipes included. 
EPIC-SOFT provided a common structure and interview interface to achieve optimised standardisation of the dietary interview procedure within and between EPIC centres. On the basis of a predefined list of food groups and sub-groups, the countries listed the single food items expected to be consumed by their participants. The open design allowed a steady modification of the food item list. In EPIC-SOFT, the following quantification methods were available for estimating portion sizes: weight/volume, food photographs (e.g. amount of fat spread on bread), standard units, household measurements, standard portions. Preliminary and country-specific data on the energy, fat, carbohydrate and alcohol contents of the food items were inserted to allow a rapid quality check at the end of the interview ${ }^{29}$. These estimates were also used in the present study for calculations on the nutrient (energy, fat) level.

The present evaluation deals with the intake of the food group 'added fats and oils'. By means of EPIC-SOFT, information on fats and oils used for cooking was collected in a highly standardised way, measured separately from the food that included them. Figure 1 provides information on the definition of food sub-groups. Most sub-groups were contained entirely in EPIC-SOFT; others were newly established (sub-groups for vegetable oils, margarines) by reclassifying country-specific food items.

In EPIC-SOFT, sauces were included in separate subgroups, i.e. 'tomato sauces', 'dressing sauces', 'dessert sauces' and 'unclassified/other sauces'. Because of its high fat content, the sub-group 'mayonnaises and similar' was not treated as a sauce (as indicated in EPIC-SOFT) but as an ordinary sub-group of fats and oils (Fig. 1). Besides information on the amount of sauces consumed, information on the type of fats and oils used for preparation of the sauces was gained systematically through the interview (facet in EPIC-SOFT). However, the quantity of the fats or oils was not solicited during the interview. The amount of lipid (nutrient) provided was computed based on standard country- or centre-specific recipes and is available for further evaluation. Therefore, the amount of fat/lipid intake by sauces and its contribution to the total intake of added fats and oils can only be considered when intake data were expressed in terms of grams of lipid per day. If several types of fats and oils were used for the preparation of one sauce, each type was said to have contributed equally. Then, the total lipid (nutrient) intake by consumption of added fats and oils, including fats and oils used as ingredients for sauce preparation, was calculated.

Crude intake values are given as the arithmetic mean, adjusted values as the mean and standard error of the mean. Adjustment within centres was performed to correct for deviations from an ideal sampling of the 24hour recalls (day of the week, season) as well as for age. For days of the week, two discrete levels (MondayFriday, Saturday-Sunday) and for season four discrete levels were chosen for weighting. Age was included as a continuous variable (regression model). Adjustment was done separately for women and men. In order to consider the differences in total energy intake between subjects, the percentage of total daily energy intake provided by lipids originating from the consumption of added fats and oils was calculated for each subject, followed by application of the same adjustment procedure as described above.

Factors significantly affecting the consumption of added fats and oils, as well as the intake of lipids originating from the consumption of fats and oils (including sauces), were identified by means of analysis of variance. For factors for which the results were not stratified, testing of statistical significance between groups was performed with the least

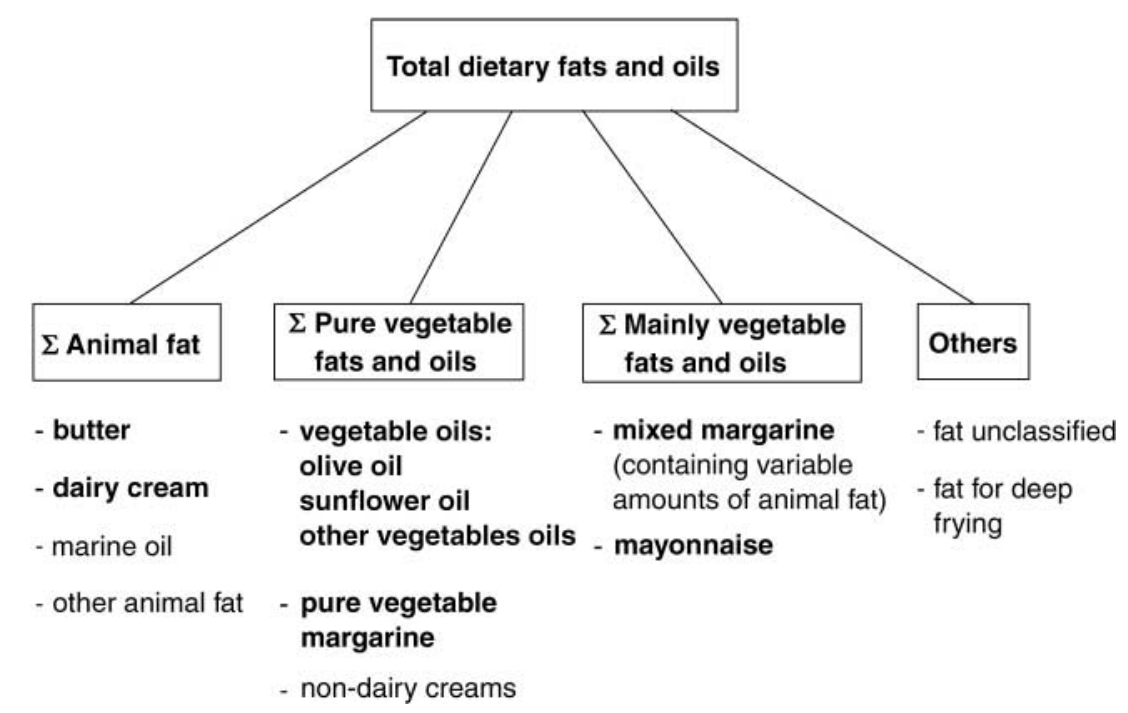

Fig. 1 Definition of sub-groups within the food group 'added fats and oils' (sub-groups in bold are given in Tables 1-4) 
significant difference (LSD) test at an $\alpha$ level of 5\%. The factors centre, day of the week and season of the recall assessment, sex, age, body mass index, smoking, education, physical activity at work and sports activity were tested. Information on the latter four variables was collected by means of questionnaires and interviews at recruitment. Calculation of adjusted values was performed using SAS System ${ }^{\circledR}$ for Windows ${ }^{\mathrm{TM}}$ (Release 8.00, SAS Institute Inc., Cary, NC, USA). All other calculations were made by means of SPSS ${ }^{\circledR}$ for Windows ${ }^{\mathrm{TM}}$ Release 10.0.7 (SPSS Inc., Chicago, IL, USA).

\section{Results}

The observed variation in mean consumption of added fats and oils between EPIC centres was quite high (Tables $1 \mathrm{a}$ and $1 \mathrm{~b}$ ). The range of mean total intake of added fats and oils was from 16.2 (Varese, Italy) to $41.1 \mathrm{~g} \mathrm{day}^{-1}$ (Malmo, Sweden) in women and from 24.7 (Ragusa, Italy) to $66.0 \mathrm{~g} \mathrm{day}^{-1}$ (Potsdam, Germany) in men (results adjusted for day of the week, season and age).

The intake of animal fat, mainly butter, was highest in the German EPIC centres, followed by centres in France and the Nordic countries. Dairy cream intake was most common in the EPIC centres of the Nordic countries Sweden, Denmark and Norway. In most Greek, Spanish and Italian centres, animal fat intake was below $3 \mathrm{~g} \mathrm{day}^{-1}$.

This contrasts with the situation found for vegetable oil intake. In the Mediterranean centres of Italy, Spain and Greece, high intake values for vegetable oils were found, with olive oil by far the largest source. The highest mean intake values were found for Spanish centres and for Greece (up to $32.3 \mathrm{~g} \mathrm{day}^{-1}$ in women and $46.5 \mathrm{~g} \mathrm{day}^{-1}$ in men). In most other EPIC centres/countries, mean vegetable oil intake was around or below $6 \mathrm{gday}^{-1}$. Sunflower oil was consumed in most EPIC centres, although at a low level. The mean intakes of other vegetable oils were fairly low $\left(<1 \mathrm{~g} \mathrm{day}^{-1}\right)$ and concentrated in certain countries (Table 2). For example, peanut oil was more often used in the EPIC centres in France and Italy, grape oil in Danish and safflower oil in German centres. Some vegetable oil (about $2 \mathrm{gday}^{-1}$ or less; except for men in Spain) could not be attributed to a unique source because the study participants either indicated unspecified 'vegetable oil' or the given oil consisted of a mixture of different oils.

The total margarine intake was reclassified owing to the high intake of margarine in several countries (Sweden, Denmark, Norway, the UK and The Netherlands), where both pure vegetable margarine and mixed-fat margarine (margarine containing a certain amount of animal fat) were available on the market (Fig. 1). The highest intake of mixed-fat margarines was found in the Swedish and Danish EPIC centres with up to $30.6 \mathrm{gday}^{-1}$ in men (Table 1). A fairly high amount of pure vegetable margarine was consumed in Potsdam (Germany), contrasting with Heidelberg (Germany). Mean daily mayonnaise intake was highest in the Danish cohorts, especially in Copenhagen, with $4.6 \mathrm{~g}$ in women and $9.3 \mathrm{~g}$ in men. In other EPIC centres/countries the mean consumption levels of mayonnaise were mostly below $3 \mathrm{~g} \mathrm{day}^{-1}$.

Evaluation of the consumption frequency of fat-reduced products revealed distinct differences between butter and margarine. In $3.8 \%$ of all reports of butter consumption, the use of fat-reduced butter was indicated with a range of $0 \%$ (Swedish centres; no fat-reduced butter on the Swedish market) to 3\% (British and German centres), except for the French (6.5\%) and Dutch (8.5\%) EPIC participants. On the contrary, fat-reduced margarines comprised almost onethird of all margarine consumption (33.8\%), covering a very high range of variation from as low as $2.7 \%$ (Danish centres) and $3.7 \%$ (British centres) up to about 30\% (Dutch centres) and 40\% (German, Swedish and Norwegian centres); for Spanish and Italian centres, the corresponding figure was about 14\%. The evaluation on the basis of lipid intake takes care of the different lipid contents in full-fat and fat-reduced butter and margarine (see below).

Overall, in about half of all reports of sauce consumption, the type of fat used for sauce preparation was specified. Specification refers largely to self-prepared dishes but was not possible for most commercial products. The highest degree of specification was reached in the French (79\%), Italian (74\%), Greek (69\%) and Spanish (48\%) EPIC centres, mainly reporting the use of olive oil. The fat specification in the EPIC centres in The Netherlands, the UK and the Nordic countries referred mainly to the use of margarine for sauce preparation. The use of dairy creams as a sauce ingredient was specified relatively often for EPIC centres in Germany and the Nordic countries (data not shown).

Considering the mean daily intake of lipids from added fats and oils, the contribution of added fats and oils in sauces to lipid intake from all fats and oils varied considerably from $0.7 \%$ (men from Murcia, Spain) up to $33.6 \%$ (men from Ragusa, Italy) (Tables $3 \mathrm{a}$ and 3b). At a country level, the contribution of lipids from sauces was highest in the French EPIC participants (27.7\%) followed by the Italians and Dutch. Sauces contributed mainly to the absolute intake of pure vegetable lipids, i.e. vegetable oils, reflecting the fact that specification of the type of fat used for sauce preparation was given mainly for salad dressings and tomato sauces (Mediterranean countries). It should be mentioned that the figures for total lipid intake by added fats and oils (Table 3) include all lipids from sauces, i.e. also all sauce items in which the fat content was not specified.

The amounts of lipid given in Table 3 are different from the amounts of food given in Table 1 . This is a reflection of the lower water content of oils compared with margarines and butter. EPIC centres with a high intake of margarine, 


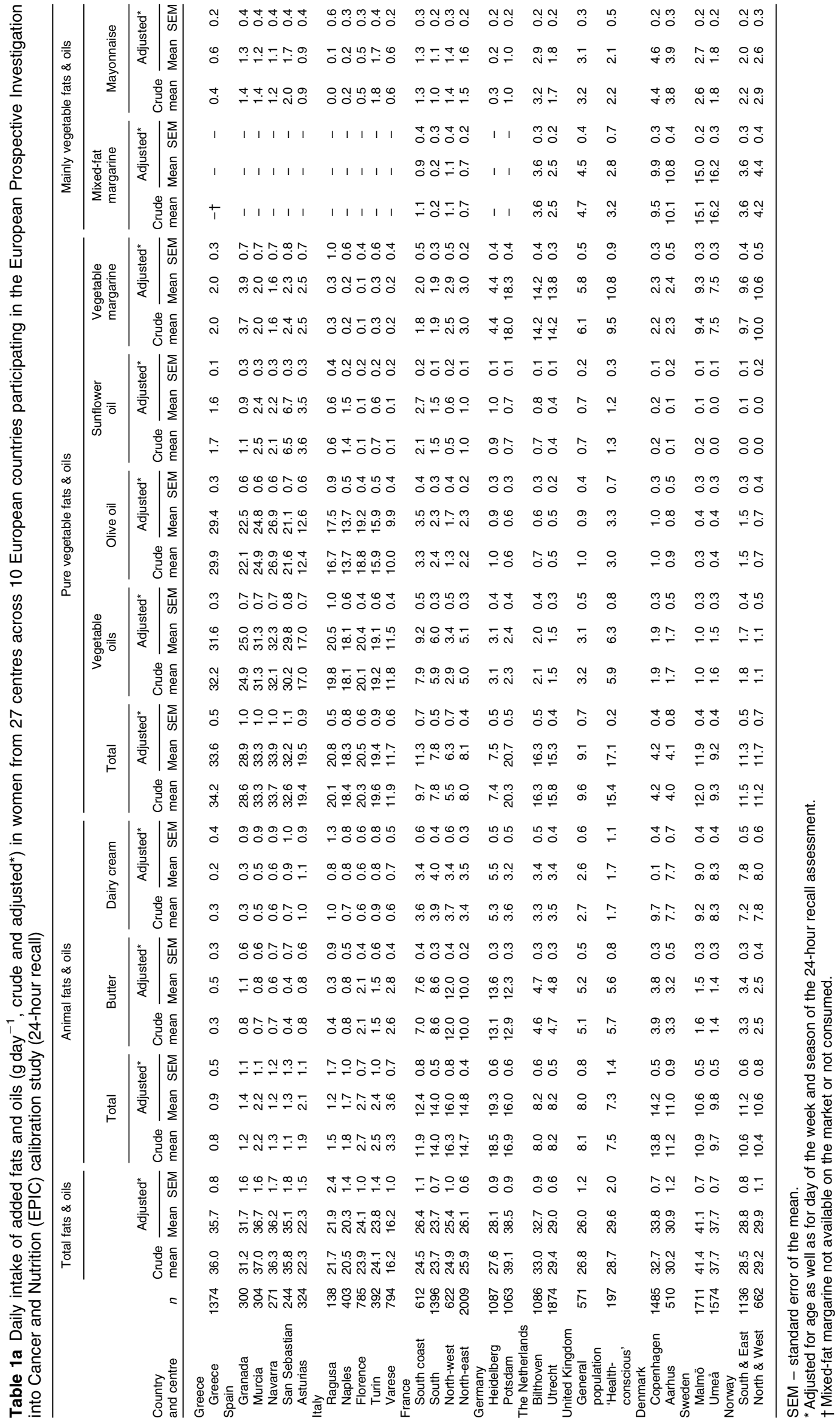


Table 2 Daily intake of vegetable oils other than olive and sunflower $\left(\mathrm{gday}^{-1}\right.$, adjusted $\left.{ }^{\star}\right)$ in women and men participating in the European Prospective Investigation into Cancer and Nutrition (EPIC) calibration study (24-hour recall) across 10 European countries

\begin{tabular}{|c|c|c|c|c|c|c|c|c|c|c|}
\hline \multirow[b]{2}{*}{ Country } & \multirow[b]{2}{*}{$n$} & & \multicolumn{8}{|c|}{ Vegetable oil } \\
\hline & & & Corn & Peanut & Grape & Rapeseed & Safflower & Soy & Walnut & Others $†$ \\
\hline \multicolumn{11}{|l|}{ WOMEN } \\
\hline \multirow[t]{2}{*}{ Greece } & 1374 & Mean & 0.47 & 0.00 & 0.00 & 0.00 & 0.00 & 0.03 & 0.00 & 0.10 \\
\hline & & SEM & 0.05 & 0.00 & 0.00 & 0.00 & 0.02 & 0.03 & 0.01 & 0.13 \\
\hline \multirow[t]{2}{*}{ Spain } & 1443 & Mean & 0.07 & 0.00 & 0.00 & 0.00 & 0.00 & 0.16 & 0.00 & 2.11 \\
\hline & & SEM & 0.05 & 0.05 & 0.04 & 0.02 & 0.00 & 0.02 & 0.00 & 0.12 \\
\hline \multirow[t]{2}{*}{ Italy } & 2512 & Mean & 0.64 & 0.50 & 0.01 & 0.00 & 0.00 & 0.13 & 0.00 & 0.55 \\
\hline & & SEM & 0.04 & 0.04 & 0.03 & 0.01 & 0.00 & 0.02 & 0.00 & 0.09 \\
\hline \multirow[t]{2}{*}{ France } & 4639 & Mean & 0.05 & 0.53 & 0.16 & 0.01 & 0.01 & 0.00 & 0.02 & 1.23 \\
\hline & & SEM & 0.03 & 0.03 & 0.02 & 0.01 & 0.01 & 0.00 & 0.00 & 0.07 \\
\hline \multirow[t]{2}{*}{ Germany } & 2150 & Mean & 0.19 & 0.00 & 0.00 & 0.00 & 0.24 & 0.00 & 0.01 & 0.70 \\
\hline & & SEM & 0.04 & 0.05 & 0.03 & 0.02 & 0.01 & 0.02 & 0.01 & 0.10 \\
\hline \multirow[t]{2}{*}{ The Netherlands } & 2960 & Mean & 0.06 & 0.03 & 0.00 & 0.00 & 0.01 & 0.02 & 0.00 & 0.48 \\
\hline & & SEM & 0.04 & 0.04 & 0.03 & 0.01 & 0.01 & 0.02 & 0.01 & 0.09 \\
\hline \multirow[t]{2}{*}{ United Kingdom } & 768 & Mean & 0.21 & 0.03 & 0.02 & 0.09 & 0.00 & 0.03 & 0.01 & 1.15 \\
\hline & & SEM & 0.07 & 0.07 & 0.05 & 0.03 & 0.02 & 0.03 & 0.01 & 0.17 \\
\hline \multirow[t]{2}{*}{ Denmark } & 1995 & Mean & 0.05 & 0.00 & 0.34 & 0.01 & 0.04 & 0.00 & 0.00 & 0.28 \\
\hline & & SEM & 0.04 & 0.04 & 0.03 & 0.02 & 0.01 & 0.02 & 0.01 & 0.10 \\
\hline \multirow[t]{2}{*}{ Sweden } & 3285 & Mean & 0.17 & 0.00 & 0.00 & 0.16 & 0.00 & 0.00 & 0.00 & 0.49 \\
\hline & & SEM & 0.03 & 0.00 & 0.02 & 0.01 & 0.01 & 0.00 & 0.01 & 0.08 \\
\hline \multirow[t]{2}{*}{ Norway } & 1798 & Mean & 0.06 & 0.03 & 0.00 & 0.01 & 0.00 & 0.17 & 0.00 & 0.00 \\
\hline & & SEM & 0.05 & 0.05 & 0.03 & 0.02 & 0.00 & 0.02 & 0.01 & 0.11 \\
\hline \multicolumn{11}{|l|}{ MEN } \\
\hline \multirow[t]{2}{*}{ Greece } & 1312 & Mean & 0.47 & 0.00 & 0.00 & 0.00 & 0.00 & 0.20 & 0.00 & 0.23 \\
\hline & & SEM & 0.07 & 0.03 & 0.03 & 0.00 & 0.00 & 0.04 & 0.00 & 0.18 \\
\hline \multirow[t]{2}{*}{ Spain } & 1777 & Mean & 0.12 & 0.00 & 0.00 & 0.00 & 0.00 & 0.09 & 0.00 & 5.73 \\
\hline & & SEM & 0.06 & 0.00 & 0.00 & 0.02 & 0.02 & 0.04 & 0.00 & 0.15 \\
\hline \multirow[t]{2}{*}{ Italy } & 1444 & Mean & 0.68 & 0.27 & 0.00 & 0.00 & 0.00 & 0.18 & 0.00 & 1.29 \\
\hline & & SEM & 0.07 & 0.02 & 0.00 & 0.02 & 0.03 & 0.04 & 0.01 & 0.17 \\
\hline \multirow[t]{2}{*}{ Germany } & 2268 & Mean & 0.14 & 0.01 & 0.00 & 0.00 & 0.29 & 0.02 & 0.02 & 0.97 \\
\hline & & SEM & 0.05 & 0.02 & 0.02 & 0.01 & 0.02 & 0.03 & 0.00 & 0.13 \\
\hline \multirow[t]{2}{*}{ The Netherlands } & 1024 & Mean & 0.08 & 0.04 & 0.00 & 0.00 & 0.02 & 0.05 & 0.00 & 1.04 \\
\hline & & SEM & 0.08 & 0.03 & 0.00 & 0.02 & 0.03 & 0.05 & 0.01 & 0.21 \\
\hline \multirow[t]{2}{*}{ United Kingdom } & 518 & Mean & 0.11 & 0.08 & 0.00 & 0.07 & 0.02 & 0.01 & 0.00 & 2.28 \\
\hline & & SEM & 0.11 & 0.04 & 0.05 & 0.03 & 0.04 & 0.07 & 0.00 & 0.28 \\
\hline \multirow[t]{2}{*}{ Denmark } & 1923 & Mean & 0.11 & 0.01 & 0.38 & 0.02 & 0.00 & 0.00 & 0.00 & 0.40 \\
\hline & & SEM & 0.06 & 0.02 & 0.03 & 0.02 & 0.02 & 0.03 & 0.00 & 0.14 \\
\hline \multirow[t]{2}{*}{ Sweden } & 2765 & Mean & 0.15 & 0.00 & 0.01 & 0.11 & 0.00 & 0.00 & 0.00 & 0.67 \\
\hline & & SEM & 0.05 & 0.02 & 0.02 & 0.01 & 0.00 & 0.00 & 0.00 & 0.12 \\
\hline
\end{tabular}

SEM - standard error of the mean.

${ }^{*}$ Adjusted for age as well as for day of the week and season of the 24-hour recall assessment.

$\dagger$ Mixtures of different oils, unspecified oils.

fat-reduced margarine or dairy cream were no longer at the top range of intake but changed positions with centres with a high vegetable oil intake, i.e. the Mediterranean centres in Greece and Spain. Looking at the ratio of lipids from animal fat to that from vegetable fat and oils, the situation did not change substantially; the highest ratio was still found for the German EPIC centres, particularly for Heidelberg.

The contribution of lipid intake (by consumption of added fats and oils including sauces) to the total daily energy intake is shown in Tables $4 \mathrm{a}$ and $4 \mathrm{~b}$. The highest mean contribution was obtained in Greece with about $22 \%$ of energy followed by the Spanish centres (about 15\% of energy on average). In most other EPIC centres/countries, women reported values of about $11 \pm 1 \%$ of energy (except Norway) and men of about $12 \pm 1 \%$ of energy. Expressed as percentage of total daily lipid (nutrient) intake, the differences in consumption of added fats and oils across EPIC centres and countries are not distinctly different from the results given in percentage of energy (Table 4). However, the Italian EPIC participants became quite similar to the Spanish ones, indicating a low contribution of total lipid intake to total energy intake in the Italian cohorts.

Total energy intake was strongly correlated with the consumption of added fats and oils. Moreover, the factors centre, smoking (three groups), education (five levels), gender, age (four groups) and season significantly ( $P<0.001$; factors in decreasing order of importance) affected fat and oil consumption, as well as lipid intake by consumption of added fats and oils including sauces. Smokers had a higher intake of fats and oils than former or never smokers (Table 5). With increasing education level, the intake values decreased. Without energy adjustment, 


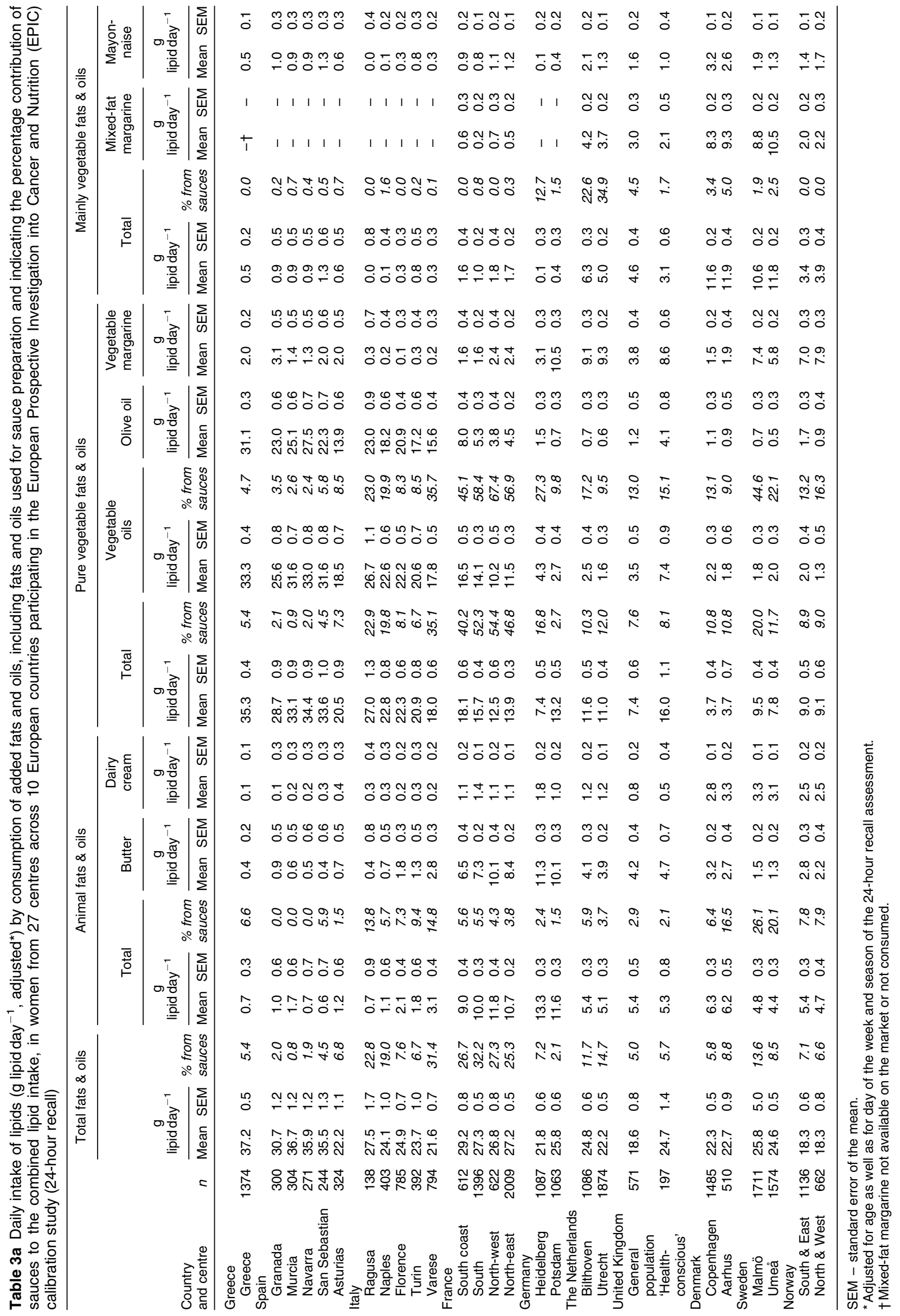




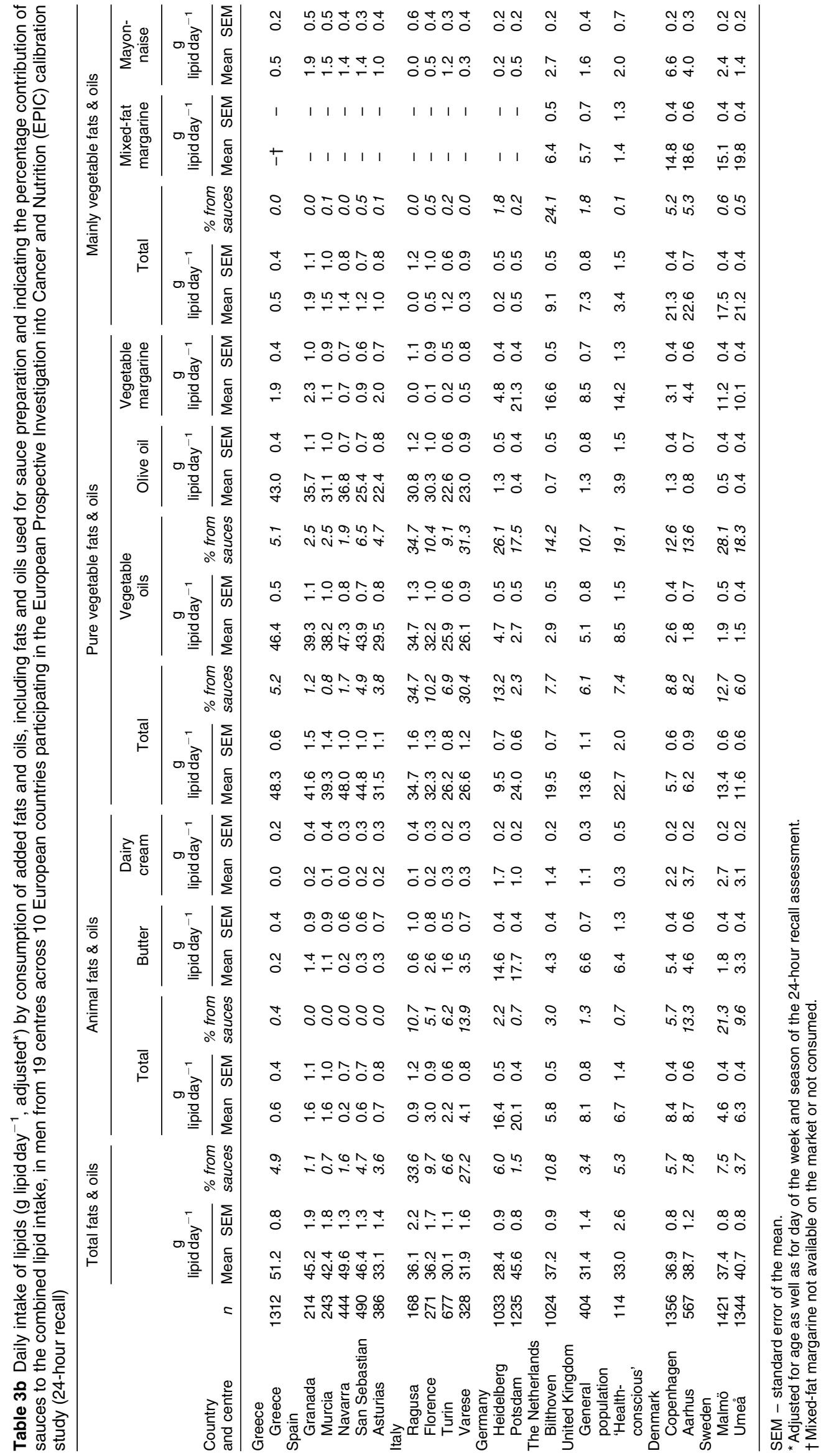




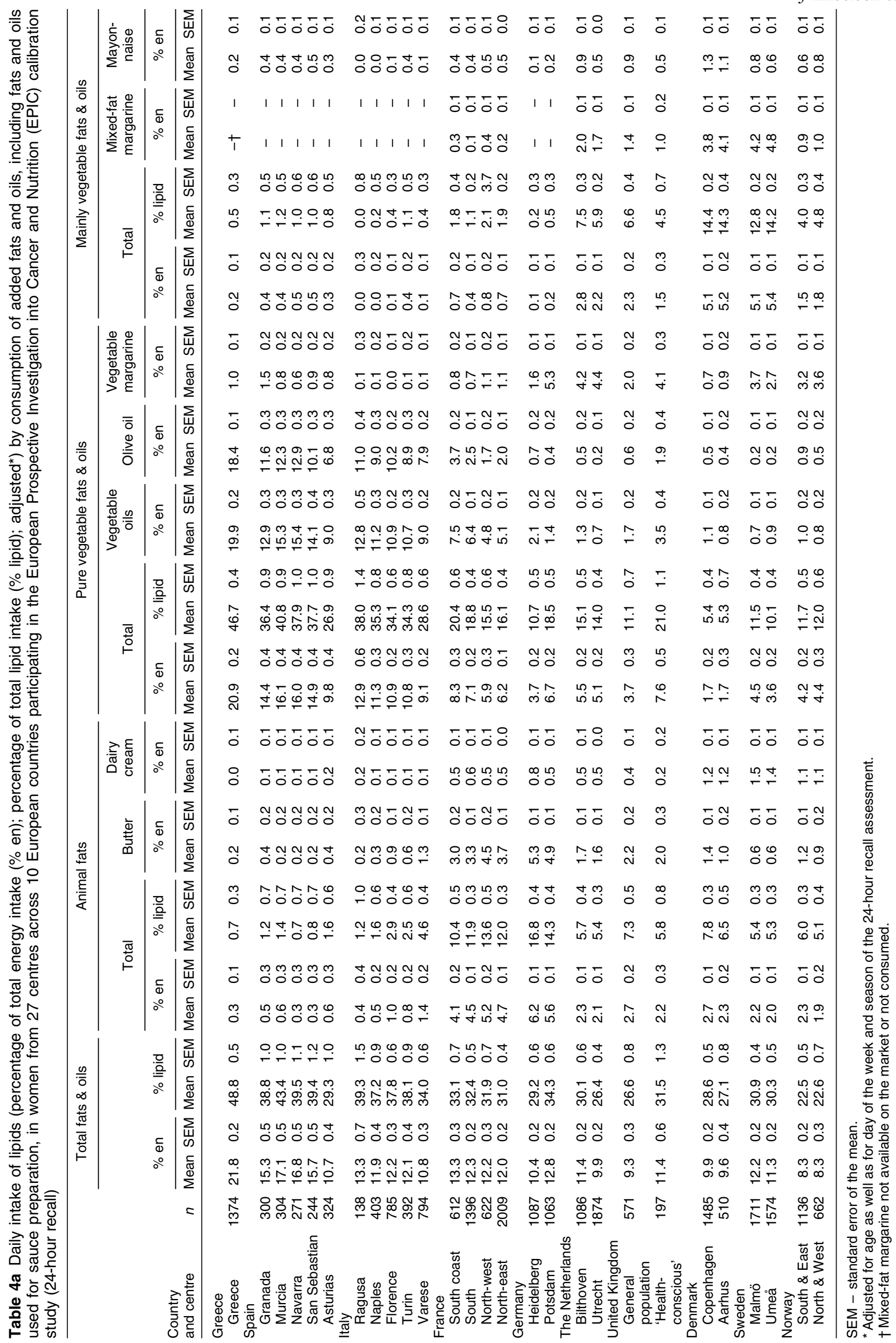




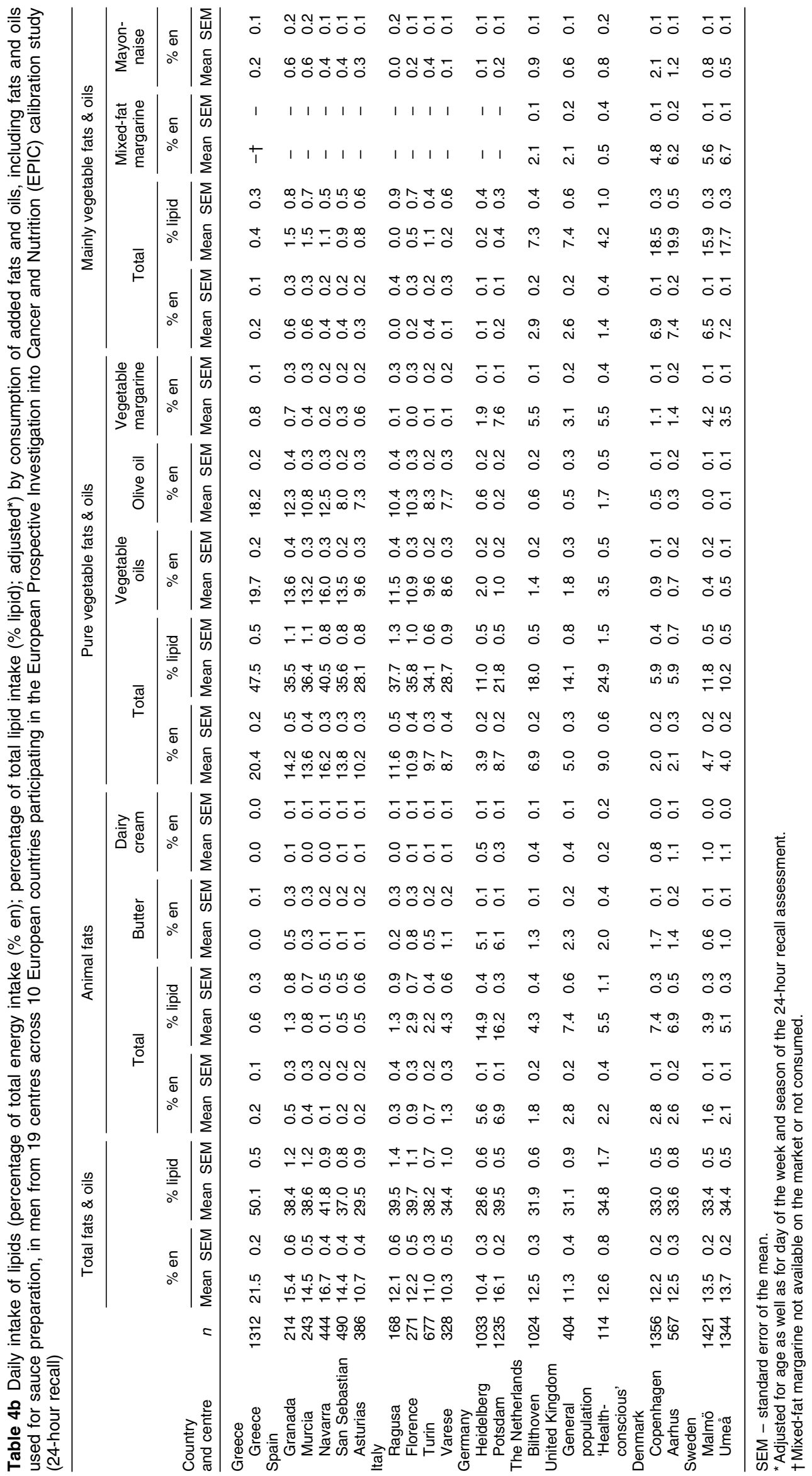


Table 5 Mean adjusted ${ }^{*}$ intake of added fats and oils $\left(\mathrm{g} \mathrm{food} \mathrm{day}^{-1}\right)$, as well as mean lipid intake ( $\mathrm{g} \mathrm{lipid} \mathrm{day}^{-1}$ ) by consumption of added fats and oils including sauces, by age class, smoking and education level, with and without inclusion of total energy intake, in women and men participating in the European Prospective Investigation into Cancer and Nutrition (EPIC) calibration study (24-hour recall)

\begin{tabular}{|c|c|c|c|c|c|c|c|c|c|c|}
\hline \multirow[b]{3}{*}{ Factor, model } & \multirow[b]{3}{*}{ Women $(n)$} & \multirow[b]{3}{*}{ Men $(n)$} & \multicolumn{4}{|c|}{$\begin{array}{l}\text { Intake of added fats and oils } \\
\left(\mathrm{g} \text { food day }{ }^{-1}\right)\end{array}$} & \multicolumn{4}{|c|}{$\begin{array}{l}\text { Lipid intake by added fats } \\
\text { and oils, including sauces } \\
\left.\text { (g lipid day }{ }^{-1}\right)\end{array}$} \\
\hline & & & \multicolumn{2}{|c|}{ Women } & \multicolumn{2}{|c|}{ Men } & \multicolumn{2}{|c|}{ Women } & \multicolumn{2}{|c|}{ Men } \\
\hline & & & Mean† & SEM & Mean† & SEM & Meant & SEM & Mean† & SEM \\
\hline \multicolumn{11}{|l|}{ AGE (years) } \\
\hline \multicolumn{11}{|c|}{ Not adjusted for energy intake: } \\
\hline $35-<45$ & 2231 & 1106 & $30.0^{\mathrm{NS}}$ & 0.9 & $46.6^{\mathrm{NS}}$ & 1.6 & $26.2^{\mathrm{NS}}$ & 0.6 & $39.0^{\mathrm{a}}$ & 1.2 \\
\hline $45-<55$ & 8597 & 3953 & 29.0 & 0.7 & 44.0 & 1.2 & 25.6 & 0.5 & $37.6^{\mathrm{a}}$ & 0.9 \\
\hline $55-<65$ & 9003 & 5910 & 28.9 & 0.7 & 44.4 & 1.1 & 25.5 & 0.5 & $38.0^{\mathrm{a}}$ & 0.8 \\
\hline $65-74$ & 3092 & 2062 & 28.9 & 0.8 & 43.1 & 1.4 & 25.0 & 0.6 & $35.6^{\mathrm{b}}$ & 1.0 \\
\hline \multicolumn{11}{|c|}{ Adjusted for energy intake: } \\
\hline $35-<45$ & 2231 & 1106 & $28.7^{\mathrm{a}}$ & 0.8 & $39.5^{\mathrm{a}}$ & 1.4 & $25.2^{\mathrm{a}}$ & 0.6 & $33.5^{\mathrm{a}}$ & 1.0 \\
\hline $45-<55$ & 8597 & 3953 & $29.2^{\mathrm{a}}$ & 0.6 & $40.7^{\mathrm{a}}$ & 1.0 & $25.7^{\mathrm{a}}$ & 0.4 & $35.1^{\mathrm{a}}$ & 0.7 \\
\hline $55-<65$ & 9003 & 5910 & $29.8^{\mathrm{a}, \mathrm{c}}$ & 0.6 & $43.3^{\mathrm{b}}$ & 1.0 & $26.3^{\mathrm{b}}$ & 0.4 & $37.2^{\mathrm{b}}$ & 0.7 \\
\hline $65-74$ & 3092 & 2062 & $30.8^{\mathrm{b}, \mathrm{c}}$ & 0.7 & $44.8^{\mathrm{b}}$ & 1.2 & $26.6^{\mathrm{b}}$ & 0.5 & $36.9^{b}$ & 0.9 \\
\hline \multicolumn{11}{|l|}{ SMOKING } \\
\hline \multicolumn{11}{|c|}{ Not adjusted for energy intake: } \\
\hline Never & 13136 & 4196 & $29.0^{\mathrm{a}}$ & 0.7 & $43.3^{\mathrm{a}}$ & 1.2 & $25.5^{\mathrm{a}}$ & 0.5 & $36.4^{\mathrm{a}}$ & 0.9 \\
\hline In the past & 5189 & 5061 & $27.3^{\mathrm{b}}$ & 0.7 & $43.1^{\mathrm{a}}$ & 1.2 & $24.2^{\mathrm{b}}$ & 0.5 & $36.5^{\mathrm{a}}$ & 0.8 \\
\hline Currently & 4135 & 3558 & $31.3^{\mathrm{c}}$ & 0.8 & $47.1^{\mathrm{b}}$ & 1.2 & $27.0^{\mathrm{c}}$ & 0.5 & $39.8^{\mathrm{b}}$ & 0.9 \\
\hline \multicolumn{11}{|c|}{ Adjusted for energy intake: } \\
\hline Never & 13136 & 4196 & $29.0^{\mathrm{a}}$ & 0.6 & $40.9^{\mathrm{a}}$ & 1.0 & $25.5^{\mathrm{a}}$ & 0.4 & $34.5^{\mathrm{a}}$ & 0.7 \\
\hline In the past & 5189 & 5061 & $28.1^{\mathrm{b}}$ & 0.6 & $41.2^{\mathrm{a}}$ & 1.0 & $24.8^{\mathrm{b}}$ & 0.5 & $34.7^{\mathrm{a}}$ & 0.7 \\
\hline Currently & 4135 & 3558 & $31.9^{\mathrm{C}}$ & 0.7 & $44.3^{\mathrm{b}}$ & 1.1 & $27.5^{\mathrm{c}}$ & 0.5 & $37.6^{\mathrm{b}}$ & 0.8 \\
\hline \multicolumn{11}{|l|}{ EDUCATION } \\
\hline \multicolumn{11}{|c|}{ Not adjusted for energy intake: } \\
\hline None & 964 & 749 & $29.4^{\mathrm{NS}}$ & 1.0 & $43.5^{\mathrm{a}, \mathrm{c}}$ & 1.6 & $25.6^{a, b}$ & 0.8 & $37.5^{\mathrm{a}}$ & 1.1 \\
\hline Primary school & 6221 & 4344 & 30.3 & 0.4 & $46.5^{\mathrm{b}, \mathrm{c}}$ & 0.8 & $26.6^{\mathrm{a}}$ & 0.3 & $40.0^{\mathrm{b}}$ & 0.6 \\
\hline Technical school & 4276 & 2913 & 29.6 & 0.5 & $47.6^{\mathrm{b}}$ & 0.9 & $25.9^{a, b}$ & 0.4 & $40.3^{\mathrm{b}}$ & 0.6 \\
\hline Secondary school & 6297 & 2092 & 28.8 & 0.4 & $43.0^{\mathrm{c}}$ & 1.0 & $25.4^{\mathrm{b}}$ & 0.3 & $37.9^{\mathrm{a}}$ & 0.7 \\
\hline University degree & 4782 & 2804 & 29.4 & 0.5 & $41.3^{\mathrm{c}}$ & 0.9 & $26.2^{\mathrm{a}, \mathrm{b}}$ & 0.4 & $36.0^{\mathrm{c}}$ & 0.6 \\
\hline \multicolumn{11}{|c|}{ Adjusted for energy intake: } \\
\hline None & 964 & 749 & $31.3^{\mathrm{a}}$ & 0.9 & $42.1^{\mathrm{a}, \mathrm{c}}$ & 1.4 & $27.1^{\mathrm{a}}$ & 0.7 & $36.4^{\mathrm{a}}$ & 1.0 \\
\hline Primary school & 6221 & 4344 & $31.3^{\mathrm{a}}$ & 0.4 & $44.7^{\mathrm{a}}$ & 0.7 & $27.5^{\mathrm{a}}$ & 0.3 & $38.4^{\mathrm{b}, \mathrm{a}}$ & 0.5 \\
\hline Technical school & 4276 & 2913 & $29.9^{\mathrm{b}}$ & 0.5 & $45.1^{\mathrm{a}}$ & 0.8 & $26.1^{\mathrm{b}}$ & 0.3 & $38.4^{b, a}$ & 0.5 \\
\hline Secondary school & 6297 & 2092 & $28.4^{\mathrm{C}}$ & 0.4 & $41.8^{b, c}$ & 0.8 & $25.1^{\mathrm{c}}$ & 0.3 & $37.1^{\mathrm{b}, \mathrm{a}}$ & 0.6 \\
\hline University degree & 4782 & 2804 & $27.6^{\mathrm{c}}$ & 0.4 & $40.4^{\mathrm{b}, \mathrm{c}}$ & 0.8 & $24.8^{c}$ & 0.3 & $35.4^{\mathrm{c}, \mathrm{a}}$ & 0.5 \\
\hline
\end{tabular}

SEM - standard error of the mean.

${ }^{*}$ Additionally adjusted for centre and season.

† Different superscripts indicate significantly different means within gender, factor and model. Vice versa, means with identical superscripts are not significantly different from each other within gender, factor and model; LSD-test, $P<0.05$. NS - not significant.

the higher age groups showed a lower intake of added fats and oils; however, the opposite is true when energy adjustment was applied.

\section{Discussion}

This paper reports quantitative estimates of dietary intake of added fats and oils (including lipids from sauce consumption) as assessed by 24-hour dietary recalls. Owing to the high standardisation of the dietary assessment tool, the results should represent reliable estimates at the group level for comparison between EPIC centres and countries. Systematically, information on fats and oils used for cooking was obtained separately from the food they were applied to. A further strength of this study is its comprehensive descriptive analysis with a complete inclusion of fats and oils used for sauce preparation. This is rarely mentioned in the literature and has therefore often been a matter of speculation. However, it must be emphasised that the results are not representative for the centre areas or the countries (with few exceptions, e.g. Norway).

No correction (e.g. exclusion from the evaluation) for under- and overreporting was made. The recalls were checked for extreme values at the end of each interview by means of the calculated daily energy intake; the correctness of the given food items had to be confirmed by the interviewed person themselves. With respect to underreporting, the extent of bias introduced by neglecting to mention foods or underestimating portion sizes is discussed elsewhere in this supplement ${ }^{30}$.

This study provides information on the lipid intake by 
consumption of added fats and oils as well as their contribution to total daily lipid and energy intakes. Since a uniform food composition table is not available for Europe, country-specific food composition data were used. As a source of bias, the calculated nutrient data may differ by the food composition table used ${ }^{24}$. This highlights the need for a common European food composition table, which is already under construction ${ }^{31}$.

A particular bias may have been introduced by the use of pictures and equivalent portion sizes related to the amount of fat spread on bread. Validation studies from the Swedish and the Dutch EPIC groups demonstrate that, by means of photographs of fats spread on bread, the amount of fat consumed on bread was overestimated ${ }^{32,33}$. Self-spread amounts were lower than the ones estimated by photographs. In terms of sub-groups, each study revealed somewhat different results. In The Netherlands, overestimation was found, especially in women, in butter users and in persons choosing a high amount of spread on bread. In Sweden overestimation was observed in men only and an influence of the type of fat was not seen. Whether overestimation of spread fat intake by means of photographs might be true for the entire EPIC 24hour recalls is not yet clear. Further insight is expected from the results of similar validation studies already being conducted in Denmark, France and Germany.

For all descriptive papers on food intake as assessed by the 24-hour recalls in EPIC, the same adjustment procedure was applied. We decided to adjust for unbalanced sampling of the 24-hour recalls (distribution over days of the week and seasons) and for age only. Analysis of variance confirmed a significant effect of age and season on the consumption of added fats and oils. As expected, energy intake was found to be strongly correlated with fat and oil consumption. Consequently, the most common way to adjust for energy intake was applied separately, i.e. presenting the intake of lipids as a percentage of total energy intake (Table 4).

One of the most apparent, although expected, results refers to the Mediterranean EPIC centres showing a high total intake of added fats and oils almost exclusively comprising olive oil while animal fat intake was very low $\left(\leq 3\right.$ g day $^{-1}$, Table 1$)$. This corresponds well to the described properties of the Mediterranean diet ${ }^{19,21,34}$. The highest olive oil consumption was found in Greece, followed by the Spanish centres (lower mean for women in Asturias) and the Italian centres (lowest mean for Varese), which is also in line with other studies ${ }^{19,21,35}$. Comparing our results with data on the availability of added lipids from the DAFNE databank reveals considerable insights in terms of identifying patterns of lipid preference $^{23}$. As already described ${ }^{36}$, the EPIC participants from France revealed a completely different intake pattern of added fats and oils, even on the South coast of France, and do not adhere to the Mediterranean style. French women consistently reported a rather high contribution of fats and oils from animal origin, which was exceeded only in the German centres. However, vegetable oil consumption - about half of which consisted of olive oil - in the French EPIC cohort was found to be much higher than in central or northern European centres.

The German centres were unique in EPIC in terms of a very high intake of animal fats. This fits well with results from German food consumption surveys ${ }^{37,38}$. While the intake of animal fats has been nearly constant over the past 50 years, there appeared to be a slight tendency towards an increase in vegetable oil consumption during the last five years ${ }^{39}$. The strong increase in margarine intake observable in the area of the former GDR after the reunification of Germany led to higher mean intake values of margarine in the Eastern part of Germany as compared with the rest of Germany. The given data demonstrate that this difference remained until 1998 and the described intake figures correspond with earlier reports ${ }^{38,40}$. Calculating a ratio of animal fat to vegetable fat, the German EPIC centres and particularly Heidelberg were at the top of the list, followed by French centres.

In the UK, a special group of so-called 'healthconscious' people was included in the EPIC study. This group included vegans as well as ovo-lacto vegetarians, fish eaters (consuming fish but no meat) and meat eaters. The difference with respect to the 'general population' refers to a somewhat higher total lipid intake by consumption of fats and oils as a consequence of a higher intake of pure vegetable lipids (vegetable oils, margarine); however, no differences in animal fat consumption were apparent. Across EPIC countries, both British cohorts were low in lipid intake from added fats and oils.

The lowest total lipid intake across all EPIC countries was observed for the female Norwegian EPIC participants regardless of the unit used (grams of lipid per day, $\%$ energy, \% lipid). This might be a consequence of the public health promotion strategy initiated very early to decrease cardiovascular mortality ${ }^{41-43}$. A decrease in the consumption of added fats and oils since the 1960s has also been described for Sweden and Denmark ${ }^{44}$.

A relatively high intake of margarine turned out to be a characteristic of the diet of EPIC participants from central and northern European centres. Whereas in Germany only pure vegetable margarine was on the market, the Swedish and Danish EPIC participants in particular reported a fairly high intake of mixed-fat margarine. The amount of animal fat in mixed-fat margarines covers a wide range from very low (e.g. through the addition of buttermilk in the UK) to $70 \%$ of the total fat content (e.g. the brand 'Bregott', full fat, which is very common in Sweden and contains $70 \%$ of fat as dairy fat and $30 \%$ as rapeseed oil). This indicates that, at least in certain EPIC centres, the amount of animal fat provided by consumption of mixed-fat margarines cannot be neglected (although a precise calculation was not possible here).

Trichopoulou and Lagiou ${ }^{45}$ suggested a categorisation 
of countries according to their per capita intake of dietary lipids (visible, i.e. added fats and oils, and invisible). Adapting this scheme to the intake patterns of added fats and oils (visible lipids) in EPIC would give the following picture. The first group, characterised by 'a high total intake of fats and oils together with a low contribution of animal fat', would best fit with the situation of the EPIC cohorts in Greece and Spain. In Italy total dietary intake of added fats and oils would be judged as 'moderate'. EPIC participants in Germany and France would be described best as being 'moderate in total fat and oil intake and high in animal fats'. All other EPIC countries would more or less be categorised as 'moderate total intake of added fats and oils together with a moderate intake of added fat of animal origin'. The latter holds true only under the assumption that mixed-fat margarines do not provide a substantial contribution to the intake of fats of animal origin; otherwise, Denmark and Sweden would reach the range of the second category.

For a rough evaluation of the fatty acid pattern of the added fats and oils consumed, knowledge of the fat sources of margarine (and non-specified vegetable oils) would be necessary. It seems likely that market prices induce the industry to use and combine the cheaper fat sources unless a certain fat source is specified on the product label. Assuming that sunflower oil and corn oil are among the dominant sources, a rather high provision of linoleic acid (C18:2n-6) would be the consequence. Then, EPIC participants from all central and northern European countries would be expected to have a high absolute intake of $n-6$ polyunsaturated fatty acids by consumption of this food group. However, rapeseed oil, which has become a more common lipid source for margarine production during the last decade, is a very good source for $\alpha$-linolenic acid $(\mathrm{C} 18: 3 n-3)$, is high in oleic acid $(\mathrm{C} 18: 1 n-9)$, and is able to modify the $n-6 / n-3$ fatty acid ratio in the total diet. On the other hand, olive oil, which is essentially a monounsaturated oil (oleic acid), dominates the Mediterranean countries. The EPIC centres in France were again different with more than $50 \%$ of the comparably high vegetable oil intake not provided by olive oil. Marine fats and oils as a source of $n-3$ long-chain polyunsaturated fatty acids in pure preparations were very rarely consumed but sometimes used as a component of margarine in the Nordic countries and in the UK. In the Norwegian EPIC cohort, cod liver oil is frequently consumed as a supplement and therefore was not included in this evaluation ${ }^{46,47}$. The implication is that the present data do not allow intakes of linoleic, $\alpha$-linolenic and long-chain $n-3$ polyunsaturated fatty acids to be estimated.

In conclusion, the present results demonstrate a rather high variation in dietary intake of added fats and oils over the EPIC centres. This provides the potential for EPIC to elucidate the role of dietary fat in terms of quantity and quality in the aetiology of cancer of different sites, an area that urgently needs scientific input and progress. The suggestion that olive oil intake is of more benefit than other dietary fats and oils in preventing cancer development ${ }^{48,49}$ can also be tested.

\section{Acknowledgements}

The work described in this paper was carried out with financial support of the 'Europe Against Cancer' Programme of the European Commission (SANCO); Ligue contre le Cancer (France); Société 3M (France); Mutuelle Générale de l'Education Nationale; Institut National de la Santé et de la Recherche Médicale (INSERM); Institute Gustave Roussy; German Cancer Aid; German Cancer Research Centre; German Federal Ministry of Education and Research; Danish Cancer Society; Health Research Fund (FIS) of the Spanish Ministry of Health; the Spanish Regional Governments of Andalucia, Asturias, Basque Country, Murcia and Navarra; Cancer Research UK; Medical Research Council, UK; Stroke Association, UK; British Heart Foundation; Department of Health, UK; Food Standards Agency, UK; Wellcome Trust, UK; Greek Ministry of Health; Greek Ministry of Education; Italian Association for Research on Cancer; Italian National Research Council; Dutch Ministry of Public Health, Welfare and Sports; Dutch Prevention Funds; LK Research Funds; Dutch ZON (Zorg Onderzoek Nederland); World Cancer Research Fund; Swedish Cancer Society; Swedish Scientific Council; Regional Government of Skane, Sweden; Norwegian Cancer Society; Norwegian Research Council. Partial support for the publication of this supplement was provided by the Centre de Recherche et d'Information Nutritionnelles (CERIN).

In addition, we wish to thank all study participants for their co-operation and all interviewers who participated in the fieldwork studies in each EPIC centre.

\section{References}

1 Simopoulos AP. Fatty acids. In: Goldberg I, ed. Functional Foods. Designer Foods, Pharmafoods, Nutraceuticals. New York: Chapman and Hall, 1998; 355-392.

2 Saris WHM, Asp NGL, Björck I, Blaak E, Bornet F, Brouns F, et al. Functional food science and substrate metabolism. Br. J. Nutr. 1998; 80(Suppl. 1): S47-75.

3 Austrup A, Grunwald GK, Melanson EL, Saris WH, Hill JO The role of low-fat diets in body weight control: a metaanalysis of ad libitum dietary intervention studies. Int J. Obes. Relat. Metab. Disord. 2000; 24: 1545-52.

4 Bray GA, Popkin BM. Dietary fat intake does affect obesity. Am. J. Clin. Nutr. 1998; 68: 1157-73.

5 Willett WC. Is dietary fat a major determinant of body fat? Am. J. Clin. Nutr. 1998; 67(Suppl.): 556S-62S.

6 Seidell JC. Dietary fat and obesity: an epidemiologic perspective. Am.J. Clin. Nutr. 1998; 67(Suppl.): 546S-50S.

7 McManus K, Antinoro L, Sacks F. A randomized controlled trial of a moderate-fat, low-energy diet compared with a lowfat, low-energy diet for weight loss in overweight adults. Int J. Obes. 2001; 25: 1503-11.

8 Law M. Dietary fat and adult diseases and the implications 
for childhood nutrition: an epidemiologic approach. Am. J. Clin. Nutr. 2000; 72(Suppl.): 1291S-6S.

9 Katan MB, Zock PL, Mensink RP. Effects of fats and fatty acids on blood lipids in humans: an overview. Am. J. Clin. Nutr. 1994; 60(Suppl.): 1017S-22S.

10 Hornstra G, Barth CA, Galli C, Mensink RP, Mutanen M, Riemersma RA, et al. Functional food science and the cardiovascular system. Br. J. Nutr. 1998; 80(Suppl. 1): S113-46.

11 Taubes G. The soft science of dietary fat. Science 2001; 291: 2536-45.

12 Hooper L, Summerbell CD, Higgins JPT, Thompson RL, Capps NE, Smith GD, et al. Dietary fat intake and prevention of cardiovascular disease: systematic review. Br. Med. J. 2001; 322: 757-63.

13 Zock PL. Dietary fats and cancer. Curr. Opin. Lipidol. 2001; 12: $5-10$.

14 Rose DP. Dietary fatty acids and cancer. Am. J. Clin. Nutr. 1997; 66(Suppl.): 998S-1003S.

15 World Cancer Research Fund/American Institute for Cancer Research (WCRF/AICR). Food, Nutrition and the Prevention of Cancer: A Global Perspective. Washington, DC: WCRF/AICR, 1997; 384-93.

16 Owen RW, Mier W, Giacosa A, Hull WE, Spiegelhalder B, Bartsch H. Phenolic compounds and squalene in olive oils: the concentration and antioxidant potential of total phenols, simple phenols, secoiridoids, lignans and squalene. Food Chem. Toxicol. 2000; 38: 647-59.

17 Molkentin J. Occurrence and biochemical characteristics of natural bioactive substances in bovine milk lipids. Br.J. Nutr. 2000; 84(Suppl. 1): S47-53.

18 Sanders TAB. Polyunsaturated fatty acids in the food chain in Europe. Am. J. Clin. Nutr. 2000; 71(Suppl.): 176S-8S.

19 Ferro-Luzzi A, Branca F. Mediterranean diet, Italian-style: prototype of a healthy diet. Am. J. Clin. Nutr. 1995; 61(Suppl.): $1338 S-45 S$.

20 Alberti-Fidanza A, Fidanza F, Chiuchiu MP, Verducci G, Fruttini D. Dietary studies on two rural Italian population groups of the Seven Countries Study. 3. Trend of food and nutrient intake from 1960 to 1991. Eur.J. Clin. Nutr. 1999; 53: 854-60.

21 Trichopoulou A, Vasilopoulou E. Mediterranean diet and longevity. Br. J. Nutr. 2000; 84(Suppl. 2): S205-9.

22 Beer-Borst S, Hercberg S, Morabia A, Bernstein MS, Galan P, Galasso R, et al. Dietary patterns in six European populations: results from EURALIM, a collaborate European data harmonization and information campaign. Eur. J. Clin. Nutr. 2000; 54: 253-62.

23 Trichopoulou A, Naska A, eds. The DAFNE initiative. Assessment of dietary patterns across Europe using household budget survey data. A European Commissionsupported project [special issue]. Public Health Nutr. 2001; 4(5B): 1129-98.

24 Deharveng G, Charrondière UR, Slimani N, Southgate DA, Riboli E. Comparison of nutrients in the food composition tables available in the nine European countries participating in EPIC. Eur. J. Clin. Nutr. 1999; 53: 60-79.

25 Slimani N, Deharveng G, Charrondière UR, van Kappel AL, Ocké MC, et al. Structure of the standardized computerized 24-h diet recall interview used as reference method in the 22 centres participating in the EPIC project. European Prospective Investigation into Cancer and Nutrition. Comput. Meth. Programs Biomed. 1999; 58: 251-66.

26 Kaaks R, Riboli E. Validation and calibration of dietary intake measurements in the EPIC project: methodological considerations. European Prospective Investigation into Cancer and Nutrition. Int. J. Epidemiol. 1997; 26(Suppl. 1): S15-25.

27 Slimani N, Kaaks R, Ferrari P, Casagrande C, Clavel-Chapelon F, Lotze G, et al. European Prospective Investigation into
Cancer and Nutrition (EPIC) calibration study: rationale, design and population characteristics. Public Health Nutr. 2002; 5(6B): $1125-45$.

28 Slimani N, Ferrari P, Ocké M, Welch A, Boeing H, van Liere $\mathrm{M}$, et al. Standardization of the 24-hour diet recall calibration method used in the European Prospective Investigation into Cancer and Nutrition (EPIC): general concepts and preliminary results. Eur. J. Clin. Nutr. 2000; 54: 900-17.

29 Voss S, Charrondière UR, Slimani N, Kroke A, Riboli E, Wahrendorf J, et al. EPIC-SOFT: a European computer program for 24-hour dietary protocols. Z. Ernährungswiss. 1998; 37: 227-33.

30 Ferrari P, Slimani N, Ciampi A, Trichopoulou D, Naska A, Lauria C, et al. Evaluation of under- and overreporting of energy intake in the 24-hour diet recalls in the European Prospective Investigation into Cancer and Nutrition (EPIC). Public Health Nutr. 2002; 5(6B): 1329-45.

31 Slimani N, Charrondière UR, van Staveren W, Riboli E. Standardization of food composition databases for the European Investigation into Cancer and Nutrition (EPIC): general theoretical concept. J. Food Comp. Anal. 2000; 13: 567-84.

32 Petterson U, Andren C, Mattison I. Fat on bread: an evaluation of photographic aids in portion size estimation. Eur. J. Clin. Nutr. 1998; 52(Suppl. 2): S30.

33 Wendel-Vos GCW, Ocké MC, Charrondière UR, Bueno-deMesquita BH. Validity of portion-size photographs of spreading bread in the Dutch part of the EPIC study. Submitted for publication.

34 Helsing E. Trends in fat consumption in Europe and their influence on the Mediterranean diet. Eur.J. Clin. Nutr. 1993; 47(Suppl. 1): S4-12.

35 Cruz JAA. Dietary habits and nutritional status in adolescents over Europe - southern Europe. Eur. J. Clin. Nutr. 2000; 54(Suppl. 1): S29-35.

36 Scali J, Richard A, Gerber M. Diet profiles in a population sample from Mediterranean southern France. Public Health Nutr. 2001; 4: 172-82.

37 Adolf T, Scheider R, Eberhardt W, Hartmann S, Herwig A, Heseker $\mathrm{H}$, et al. Ergebnisse der Nationalen Verzebrsstudie (1985-1988) über die Lebensmittel- und Näbrstoffaufnabme in der Bundesrepublik Deutschland. VERA-Schriftenreihe XI. Niederkleen: Wissenschaftlicher Fachverlag Dr. Fleck, 1995.

38 Winkler G, Brasche S, Döring A, Heinrich J. Dietary intake of middle-aged men from an East and a West German city after reunification: do differences still exist? Eur. J. Clin. Nutr. 1998; 52: 98-103.

39 German Nutrition Society. Nutrition Report 2000. Frankfurt am Main: Henrich GmbH, 2000.

40 Hirsch T, Kempe G. Consumption of omega-3 and omega -6 fatty acids in former East and West Germany and changes in East Germany after the reunification. Respir. Med. 1999; 93: 213-6.

41 World Health Organization (WHO). Diet, Nutrition and the Prevention of Chronic Diseases. Technical Report Series No. 797. Geneva: WHO, 1990.

42 Johansson L, Thelle DS, Solvoll K, Bjorneboe GE, Drevon CA. Healthy dietary habits in relation to social determinants and lifestyle factors. Br. J. Nutr. 1999; 81: 211-20.

43 Johansson L, Drevon CA, Bjorneboe GE. The Norwegian diet during the last hundred years in relation to coronary heart disease. Eur. J. Clin. Nutr. 1996; 50: 277-83.

44 Groth MV, Fagt S. Trends in dietary habits in Denmark and Sweden since the 1960s. Ugeskr. Laeger 2001; 163: 425-9.

45 Trichopoulou A, Lagiou P. Worldwide pattern of dietary lipids intake and health implications. Am.J. Clin. Nutr. 1997; 66(Suppl.): 961S-4S. 
46 Johansson LR, Solvoll K, Bjorneboe GE, Drevon CA. Intake of very-long-chain $n-3$ fatty acids. Eur. J. Clin. Nutr. 1998; 52: 716-21.

47 Hjartaker A, Lund E. Relationship between dietary habits, age, lifestyle, and socio-economic status among adult Norwegian women. The Norwegian Women and Cancer Study. Eur. J. Clin. Nutr. 1998; 52: 565-72.
48 Kushi LH, Lenart EB, Willett WC. Health implications of Mediterranean diets in light of contemporary knowledge. 2. Meat, wine, fats, and oils. Am.J. Clin. Nutr. 1995; 61(Suppl.): 1416S-27S

49 Trichopoulou A, Lagiou P, Kuper H, Trichopoulos D. Cancer and Mediterranean dietary traditions. Cancer Epidemiol. Biomark. Prev. 2000; 9: 869-73. 